12,18

\title{
Синтез полых углеродных нанооболочек и их применение для суперконденсаторов
}

\author{
(ㄷ Г.А. Рудаков ${ }^{1}$, А.В. Сосунов ${ }^{1, \pi}$, Р.С. Пономарев ${ }^{1}$, В.К. Хеннер ${ }^{1}$, Md. Shamin Reza ${ }^{2}$, Gamini Sumanasekera ${ }^{2}$ \\ ${ }^{1}$ Пермский государственный национальный исследовательский университет, \\ Пермь, Россия \\ ${ }^{2}$ Department of Physics and Astronomy, University of Louisville, \\ Louisville, United States \\ I E-mail: alexeisosunov@gmail.com
}

(Поступила в Редакцию 11 апреля 2017 г.)

\begin{abstract}
Работа посвящена исследованию особенностей синтеза, описанию структуры и применению полых углеродных нанооболочек размером 3-5 $\mathrm{nm}$. Синтез полых углеродных нанооболочек проводили методом термолиза смеси ацетата никеля и лимонной кислоты в температурном интервале $500-700^{\circ} \mathrm{C}$. В ходе химической реакции происходит образование зародышей никеля размером $\sim 3-5 \mathrm{~nm}$, отделенных друг от друга углеродными слоями. При температуре отжига $600^{\circ} \mathrm{C}$ образуется наиболее упорядоченная, плотноупакованная структура, равномерно распределенная по всему объему образца. В результате вытравливания никеля азотной кислотой были получены полые углеродные нанооболочки с высокой удельной площадью поверхности $\left(\sim 1200 \mathrm{~m}^{2} / \mathrm{g}\right)$ и однородной структурой. Методом спектроскопии комбинационного рассеяния света показано, что графеноподобная структура углеродных нанооболочек до и после вытравливания никеля сохраняется, а их дефектность не увеличивается, что позволяет подвергать их новой обработке (функционализации) с целью получения дополнительных физических свойств. Полученные углеродные нанооболочки использовали в качестве активного материала электродов для суперконденсатора. Проведенные электрохимические измерения показали, что удельная емкость суперконденсатора не опускается ниже $100 \mathrm{~F} / \mathrm{g}$ при плотности тока $600 \mathrm{~mA} / \mathrm{g}$ после 800 циклов зарядки/разрядки.
\end{abstract}

Работа выполнена при финансовой поддержке Российского фонда фундаментальных исследований (грант № 17-42-590271) и Фонда содействия развитию малых форм предприятий в научно-технической сфере (грант № 0033507).

DOI: 10.21883/FTT.2018.01.45304.127

\section{1. Введение}

Углерод может существовать в различных аллотропных модификациях и обладать набором уникальных физических свойств. Разнообразие модификаций углерода обусловлено его способностью иметь химические связи разных типов.

Углеродные материалы широко применяются в медицине, химии и энергетике [1]. Возможности применения в разных областях науки и техники привели к необходимости исследования структуры, физических и химических свойств углеродных материалов [2-4]. Известно, что углерод с графитовой структурой, где хорошо развита кристаллическая фаза, имеет ряд преимуществ по сравнению с аморфным углеродом изза высокой электрической проводимости, термической стабильности и слабого окисления [5].

В последние годы значительный успех был достигнут в получении сферических графитовых наноматериалов. Данный класс наноматериалов включает в себя фуллерены и углеродные нанооболочки (УНО), однако фуллерены в отличие от УНО существуют главным образом в виде отдельных наноструктур. Графитовые УНО образуют трехмерную пеноподобную структуру с большой удельной площадью поверхности. Таким образом, УНО наиболее предпочтительны для применения в доставке лекарственных препаратов [6-8], разделении газов [9], в топливных элементах [10-12] и для очистки воды [13]. Наиболее перспективно применение УНО в качестве материала для изготовления электродов в суперконденсаторах и литий-ионных батареях высокой емкости, которые демонстрируют стабильность характеристик при многократной перезарядке [14-18].

Существуют разные методы получения углеродных наноматериалов (нанотрубок, наносфер, нановолокон, наночастиц), такие как лазерное испарение [19-22], химическое осаждение из газовой фазы [23,24], электродуговой разряд [25]. Однако в большинстве своем эти методы довольно сложны и не всегда позволяют получать наноматериал с высокой удельной площадью поверхности, что является крайне важным для его применения в качестве электродов для суперконденсаторов и литий-ионных батарей. В настоящей работе мы использовали метод термолиза [17,26-29], который является простым и эффективным способом получения УНО.

Целью данной работы является синтез УНО методом термолиза смеси ацетата никеля и лимонной кислоты, поиск наиболее оптимальной температуры отжига для получения УНО с высокой степенью однородности и стабильности свойств, а также исследование возможности использования их в качестве материала для суперконденсаторов, аккумуляторов и батарей. 


\section{2. Изготовление образцов}

Наночастицы никеля и УНО были синтезированы методом термолиза. Сначала подготавливали водный раствор из смеси порошков тетрагидрата ацетата никеля $\mathrm{Ni}\left(\mathrm{CH}_{3} \mathrm{CO}_{2}\right)_{2} \cdot 4 \mathrm{H}_{2} \mathrm{O}$ производства Sigma-Aldrich и лимонной кислоты $\mathrm{C}_{6} \mathrm{H}_{8} \mathrm{O}_{7}$ в равных массовых пропорциях. Далее подготовленный водный раствор высушивали в сушильном шкафу при $90^{\circ} \mathrm{C} 10-15 \mathrm{~h}$ до полного испарения воды. Затем получившийся порошок помещали в керамический тигель и отжигали в трубчатой печи с непрерывным потоком азота (скорость потока $70-80 \mathrm{~cm}^{3} / \mathrm{min}$ ). Три различных образца были получены с помощью отжига при 500,600 и $700^{\circ} \mathrm{C}$ в течение $10 \mathrm{~min}$, скорость нагрева печи $50^{\circ} \mathrm{C} / \mathrm{min}$. После отжига образцы охлаждали вместе с печью до комнатной температуры, чтобы избежать возможного окисления. Данный метод позволяет получить массив наночастиц никеля, окруженных определенным количеством слоев УНО. После отжига образцы обрабатывали в 70\%-ном растворе азотной кислоты при $80^{\circ} \mathrm{C}$ в течение $8-10 \mathrm{~h}$ для удаления никеля. Далее образцы промывали этанолом, а затем дистиллированной водой.

\section{3. Методы исследования}

Микроструктуру полученных образцов исследовали с помощью сканирующего электронного микроскопа (CЭM) ZEISS Supra 35 EVO при ускоряющем напряжении 5-20kV. В качестве датчика использовали специализированный высокоразрешающий детектор InLens. Состав и наноструктура синтезируемых образцов были охарактеризованы с помощью просвечивающего электронного микроскопа (ПЭМ) FEI F20 Tecnai с возможностью энерго-дисперсионного рентгеновского анализа и сканирования поверхности. В качестве источника электронов использовали полевую эмиссионную пушку. Измерения проводили при ускоряющем напряжении $200 \mathrm{kV}$. Удельная площадь поверхности была определена методом Брунауэра, Эммета и Теллера с использованием Micromeritics TriStar 3000. Структуру углеродных слоев до и после вытравливания никеля изучали с помощью спектроскопии комбинационного рассеяния света с использованием $\mathrm{He}-\mathrm{Ne}$ лазера в спектральном диапазоне $800-3500 \mathrm{~cm}^{-1}$, работающем на длине волны $632 \mathrm{~nm}$ (Renishaw inVia Raman system).

\section{4. Результаты и их обсуждение}

На рис. 1 представлены результаты ПЭМ образцов, полученных в температурном интервале $500-700^{\circ} \mathrm{C}$. При температуре отжига $500^{\circ} \mathrm{C}$ образуется массив сферических наночастиц углерод/никель диаметром $\sim 3-5 \mathrm{~nm}$. Видно, что никелевые наночастицы покрыты ультратонкими УНО, представляющими собой графитовый слой, который отделяет одну наночастицу от другой.
Элементный состав образцов

\begin{tabular}{c|c|c|c}
\hline \multirow{2}{*}{$\begin{array}{c}\text { Температура } \\
\text { отжига, }{ }^{\circ} \mathrm{C}\end{array}$} & \multicolumn{3}{|c}{ Состав образцов до травления } \\
\cline { 2 - 4 } & Элемент & $\mathrm{Wt} \%$ & $\mathrm{At} \%$ \\
\hline \multirow{3}{*}{500} & $\mathrm{C}$ & 10 & 35 \\
& $\mathrm{O}$ & 1 & 3 \\
& $\mathrm{Ni}$ & 89 & 62 \\
\hline \multirow{3}{*}{600} & $\mathrm{C}$ & 41 & 75 \\
& $\mathrm{O}$ & 3 & 4 \\
& $\mathrm{Ni}$ & 56 & 21 \\
\hline \multirow{3}{*}{700} & $\mathrm{C}$ & 71 & 87 \\
& $\mathrm{O}$ & 7 & 7 \\
& $\mathrm{Ni}$ & 22 & 6
\end{tabular}

Однако наноструктура в целом не выглядит однородной и плотноупакованной, так как имеются вакансии никеля и пустоты (поры). При температуре отжига $600^{\circ} \mathrm{C}$ образуется массив наночастиц углерод/никель диаметром 3-5 nm, но наноструктура уже более однородная, стабильная и плотноупакованная по всему объему образца. При повышении температуры синтеза до $700^{\circ} \mathrm{C}$ появляются более крупные наночастицы никеля размером 20-50 nm, покрытые толстым слоем УНО из 10-20 слоев, т.е. с повышением температуры никелю энергетически выгодно агломерироваться, образуя наночастицу с гораздо бо́льшими диаметром и количеством углеродных слоев. Оставшийся объем заполняется углеродом.

Структурные особенности, связанные с температурной обработкой, отражены и в электронограммах (рис. 1). При $700^{\circ} \mathrm{C}$ на электронограмме кроме кольцевых непрерывных полос появляются еще дополнительные дифракционные пятна, что свидетельствует о росте размера наночастиц, чего не наблюдается при более низких температурах отжига. В таблице представлены результаты элементного состава полученных образцов. Заметна следующая тенденция: с ростом температуры доля никеля сокращается, а для углерода увеличивается. Эти данные хорошо согласуются с тем, что с ростом температуры происходит формирование крупных наночастиц никеля, окруженных бо́льшим количеством слоев УНО.

На рис. 2 представлены результаты СЭМ образцов, отожженных в температурном интервале 500-700 ${ }^{\circ} \mathrm{C}$. Отчетливо наблюдаются стержни, состоящие из наночастиц углерод/никель для всех образцов, что мы и наблюдали при среднем увеличении $(50 \mathrm{~nm})$ на ПЭМ (рис. 1). Толщина этих стержней колеблется в диапазоне 400-700 nm. Такие материалы в виде стержней на основе углерода могут применяться для нанокондесаторов [30]. На рис. 2, с отчетливо наблюдаются белые точки на поверхности образца. Это наночастицы углерод/никель размером 50-100 $\mathrm{nm}$.

Образцы, полученные при $600^{\circ} \mathrm{C}$, использовали для получения полых УНО. Морфология и структура полу- 


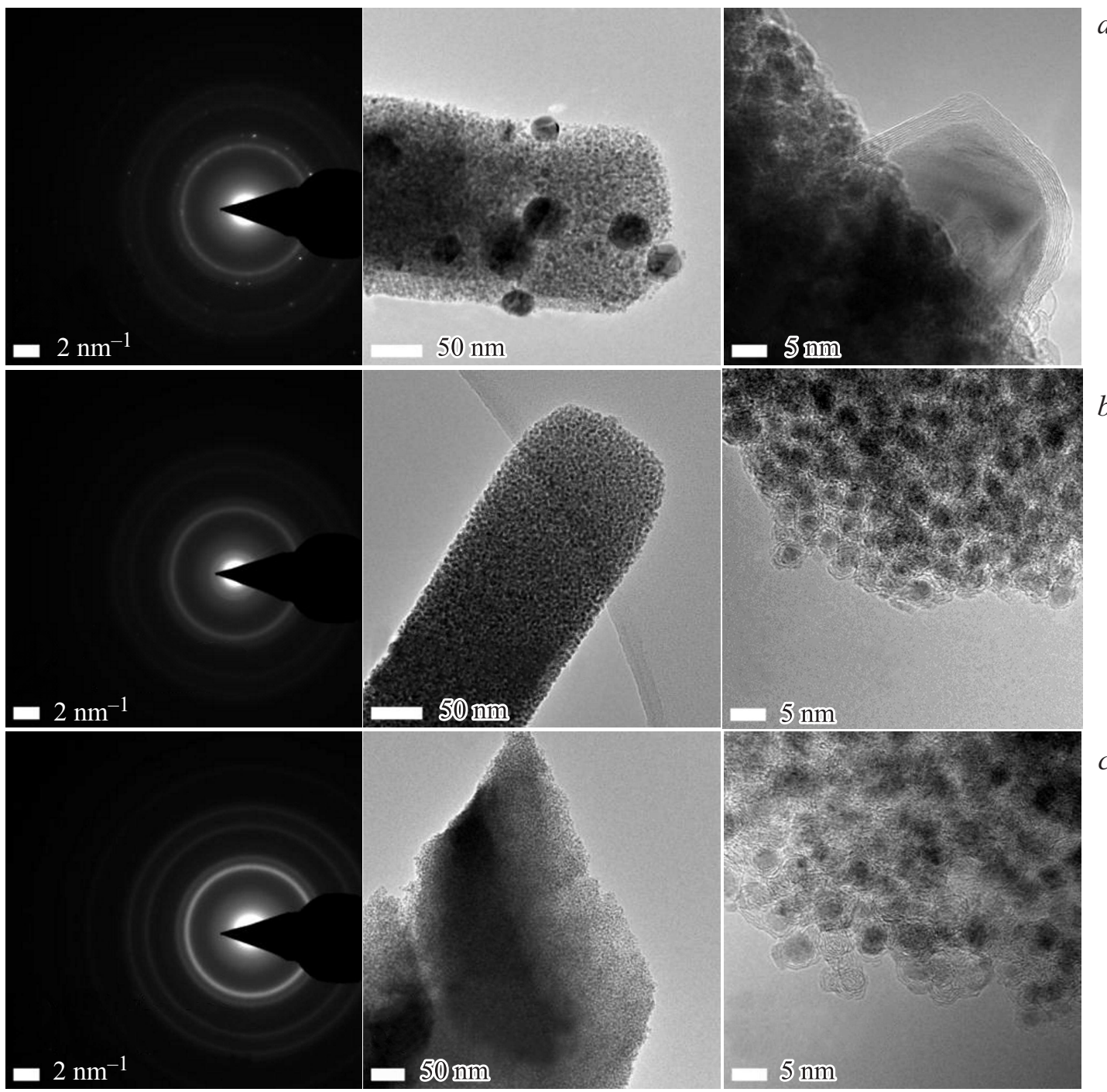

Рис. 1. Результаты ПЭМ для образцов, отожженных при $500(a), 600(b), 700^{\circ} \mathrm{C}(c)$. Для каждого образца представлены результаты при среднем и сверхвысоком увеличении, а также результаты дифракции электронов с выбранной области.

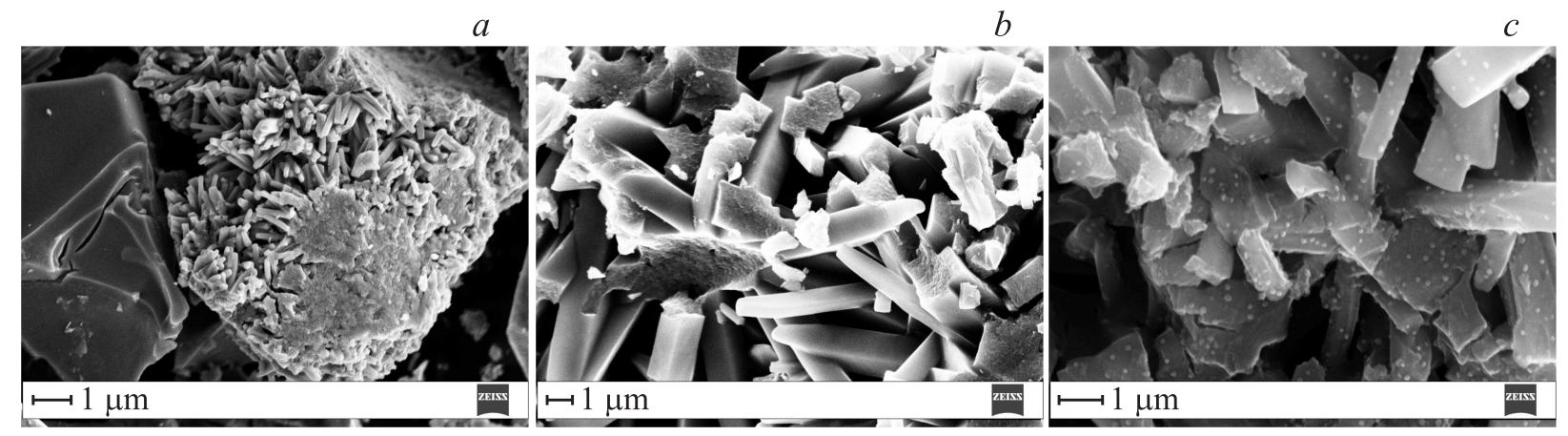

Рис. 2. Микроструктура образцов, отожженных при $500(a), 600(b), 700^{\circ} \mathrm{C}(c)$.

ченных УНО представлены на рис. 3. Образец состоит из большого массива полых УНО диаметром 2-3 nm, равномерно распределенных по всему объему образца. Элементный анализ УНО после травления образцов в азотной кислоте показал отсутствие никеля, а соотношение кислород/углерод составило 1:10. УНО имеют 2-3 углеродных слоя с кислородными дефектами и образуют трехмерную структуру. Определена удельная 

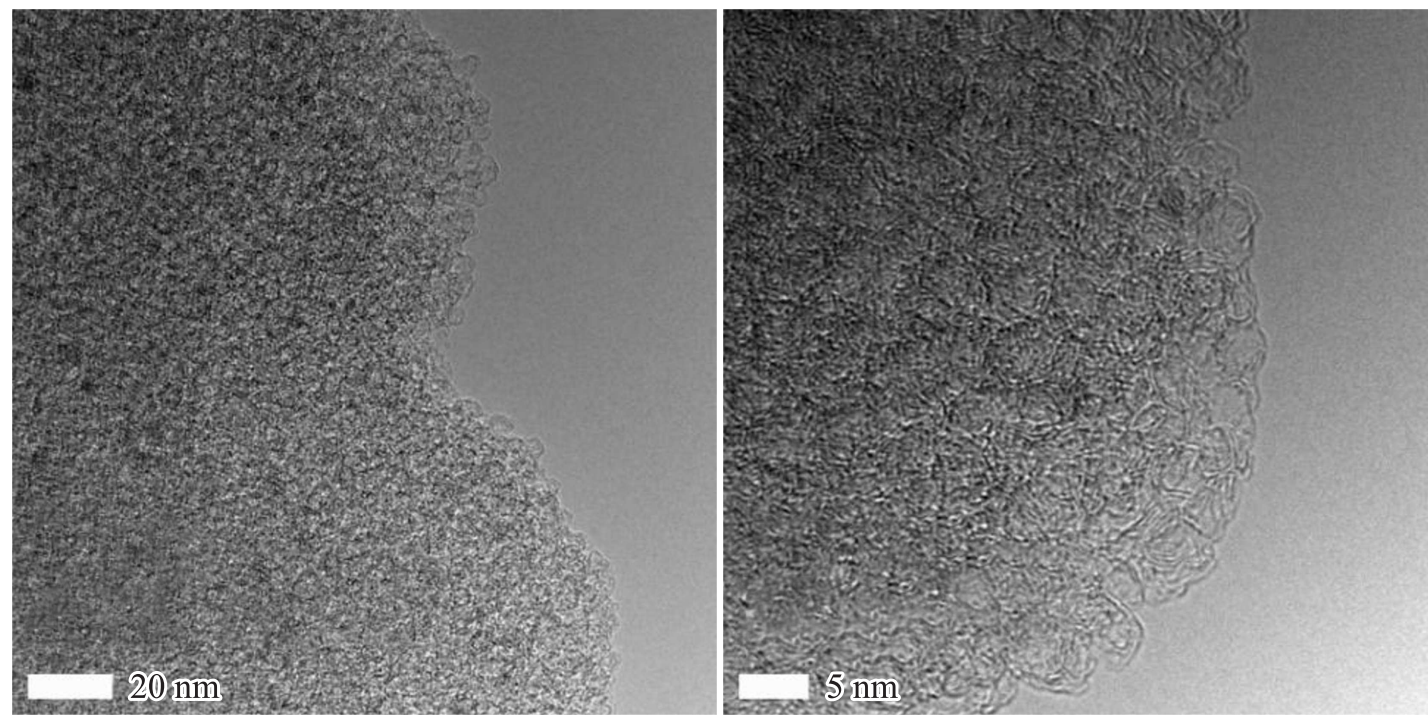

Рис. 3. Морфология и наноструктура полых УНО после удаления никеля для образца, полученного при $600^{\circ} \mathrm{C}$.

площадь поверхности образца методом Брунауэра, Эммета и Теллера $\left(\sim 1200 \mathrm{~m}^{2} / \mathrm{g}\right)$, что подтверждает высокую пористость структуры материала.

Изучение структуры синтезируемых образцов при различных температурах отжига до и после удаления никеля производили методом спектроскопии комбинационного рассеяния (рис. 4). Образцы имеют графеноподобную структуру как до, так и после удаления никеля, т.е. структура образцов сохраняется после травления, при этом температура отжига не оказывает сильного влияния на эти процессы. Данный факт позволяет проводить дополнительную обработку образцов, например функционализацию [31,32] в различных атмосферах. Спектр состоит из четырех основных полос, $\sim 1300$ (D пик), 1600 ( $\mathrm{G}$ пик), 2700 (2D пик) и 2900 (D+G пик) $\mathrm{cm}^{-1}$. Первым наиболее интенсивным является D пик, который изначально имел смысл наличия алмазоподобной структуры в конфигурации $s p^{3}$ [33], однако позднее было установлено, что в графитовых структурах D пик характеризует степень неупорядоченности [34], вызванной конечными размерами кристаллитов и дефектов. Следующим наиболее интенсивным является $G$ пик. $G$ группа возникает из-за растяжения связи $\mathrm{C}-\mathrm{C}$ в графитовых материалах и является общей для всех систем $s p^{2}$ углерода (режим $E_{2 g}$ в Г-точке) [33-36]. Все виды $s p^{2}$ углеродных материалов демонстрируют полосы в диапазоне $2500-2900 \mathrm{~cm}^{-1}$ в спектрах комбинационного рассеяния. 2D полоса комбинационного рассеяния - это полоса второго порядка D пика [34], которая сильно зависит от частоты лазерного возбуждения энергии и в большинстве случаев указывает на существование графеновых структур. Ширина этого пика связана с наличием нескольких прилегающих друг к другу слоев графена [37]. Такую конфигурацию мы и получили для полых УНО. Пик $\mathrm{D}+\mathrm{G}$ также характеризует
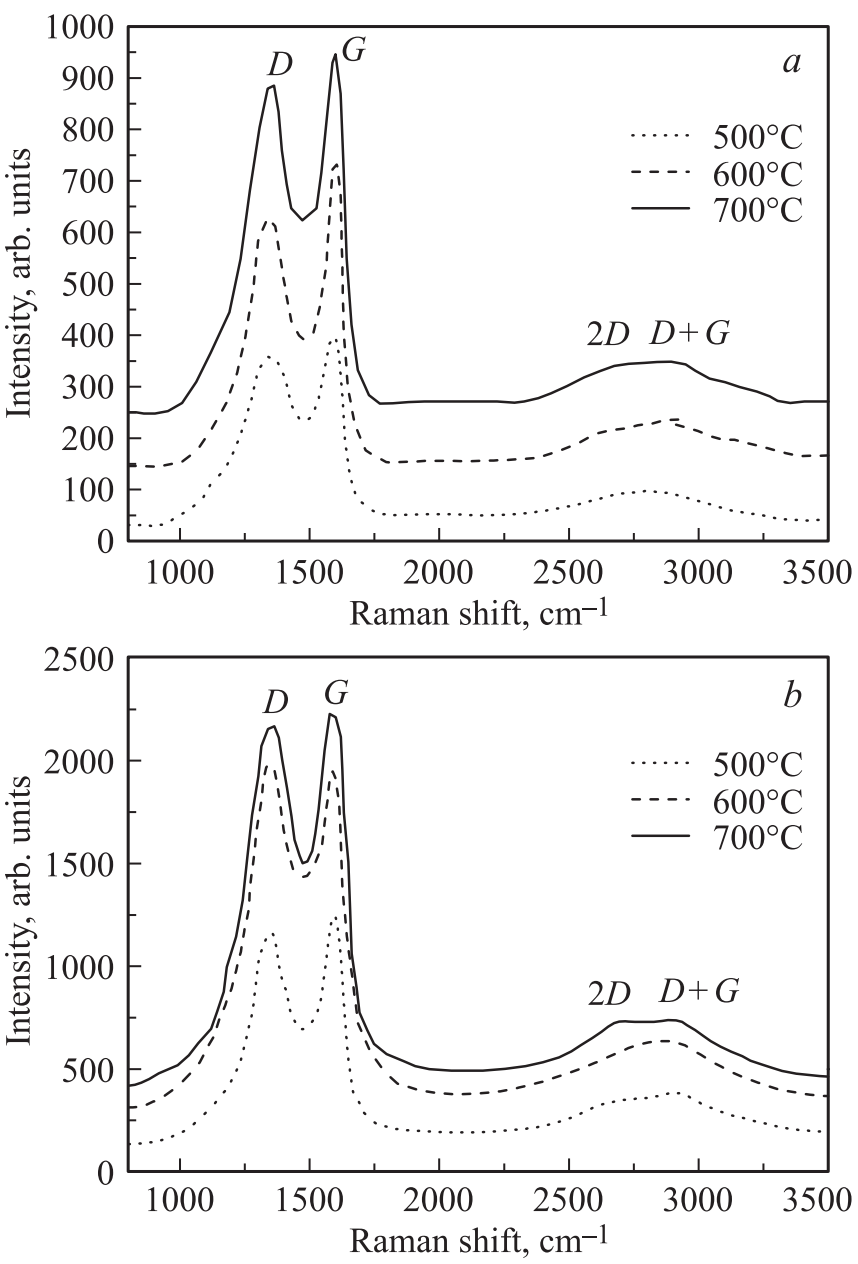

Рис. 4. Результаты спектроскопии комбинационного рассеяния света для образцов, полученных при различной температуре отжига до и после удаления никеля до травления $(a)$, после травления $(b)$. 


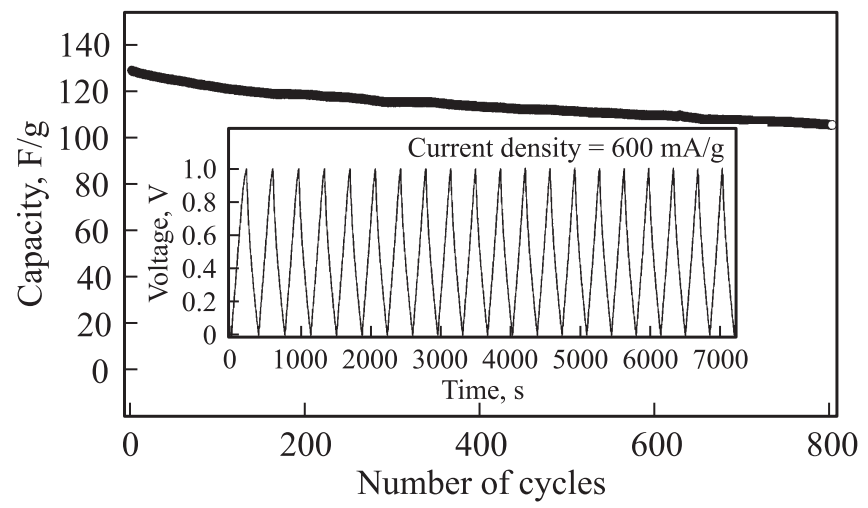

Рис. 5. Циклические характеристики производительности суперконденсатора при плотности тока $600 \mathrm{~mA} / \mathrm{g}$ для первых 800 циклов. Соответствующие гальваностатические кривые заряд/разряд показаны на вставке (для удобства показаны только начальные 20 циклов).

разупорядочение структуры, наличие дефектов, однако в работах [36,37] сообщалось о валентных $s p^{2}$ и $s p^{3}$ колебаниях $\mathrm{C}-\mathrm{H}$.

Электрохимические измерения проводили на основе полученных при $600^{\circ} \mathrm{C}$ УНО для оценки производительности предложенных нами суперконденсаторов. Электроды были изготовлены следующим образом: $90 \mathrm{wt. \%}$ УНО с 2 wt.\% тефлонированной ацетиленовой сажи (ТАВ) и $8 \%$ поливинилиденфторида (PVDF) помещали в раствор N-метил-2-пирролидона (NMP). Хорошо перемешанную суспензию наносили на алюминиевую фольгу, а затем высушивали при $180^{\circ} \mathrm{C}$ в течение $3 \mathrm{~h}$ в вакууме. Суперконденсатор был испытан с использованием $6 \mathrm{M}$ раствора $\mathrm{KOH}$ в качестве электролита. Роль сепаратора выполняла целлюлоза, пропитанная $\mathrm{KOH}$. На рис. 5 показаны результаты измерения характеристик суперконденсатора с полной зарядкой и разрядкой от 0 до $1.0 \mathrm{~B}$ при плотности тока $600 \mathrm{~mA} / \mathrm{g}$. Для электриче- ской двухслойной емкости характерно почти линейное отношение напряжение/время. Существует небольшое искажение кривых, предположительно, вызванное псевдоемкостью функциональных групп. Удельную емкость электродов рассчитывали по формуле

$$
C=\frac{4 I \Delta t}{m \Delta V}
$$

где $I, \Delta t, m$ и $\Delta V-$ приложенный ток, время разряда, общая масса активного материала и изменение напряжения соответственно. Емкость первого цикла составляет $130 \mathrm{~F} / \mathrm{g}$ с деградацией на $23 \%$ после 800 циклов (рис. 5). На рис. 6 показано сравнение производительности суперконденсаторов при изменении плотности тока 300 , $600 \mathrm{~mA} / \mathrm{g}, 1.5$ и $3 \mathrm{~A} / \mathrm{g}$. Даже при самой высокой плотности тока $3 \mathrm{~A} / \mathrm{g}$ суперконденсатор сохраняет удельную емкость $\sim 120 \mathrm{~F} / \mathrm{g}$. Полученный образец суперконденсатора показывает хорошие характеристики и может быть использован в достаточно мощных устройствах.

\section{5. Заключение}

Методом термолиза смеси ацетата никеля и лимонной кислоты получены дисперсные наночастицы углерод/никель размером $3-5 \mathrm{~nm}$ в температурном интервале $500-700^{\circ} \mathrm{C}$. При $600^{\circ} \mathrm{C}$ структура является наиболее однородной, стабильной и плотноупакованной по всему объему образца. Методом СЭМ показано наличие наностержней на поверхности образцов. С помощью изменения температуры синтеза можно управлять размером наночастиц.

Получены полые УНО, которые сохраняют свою структуру и свойства после удаления никеля, что позволит подвергать их новой обработке с целью придания дополнительных физических свойств. УНО производили из образцов, сформированных при $600^{\circ} \mathrm{C}$. Удельная площадь поверхности составила $\sim 1200 \mathrm{~m}^{2} / \mathrm{g}$.
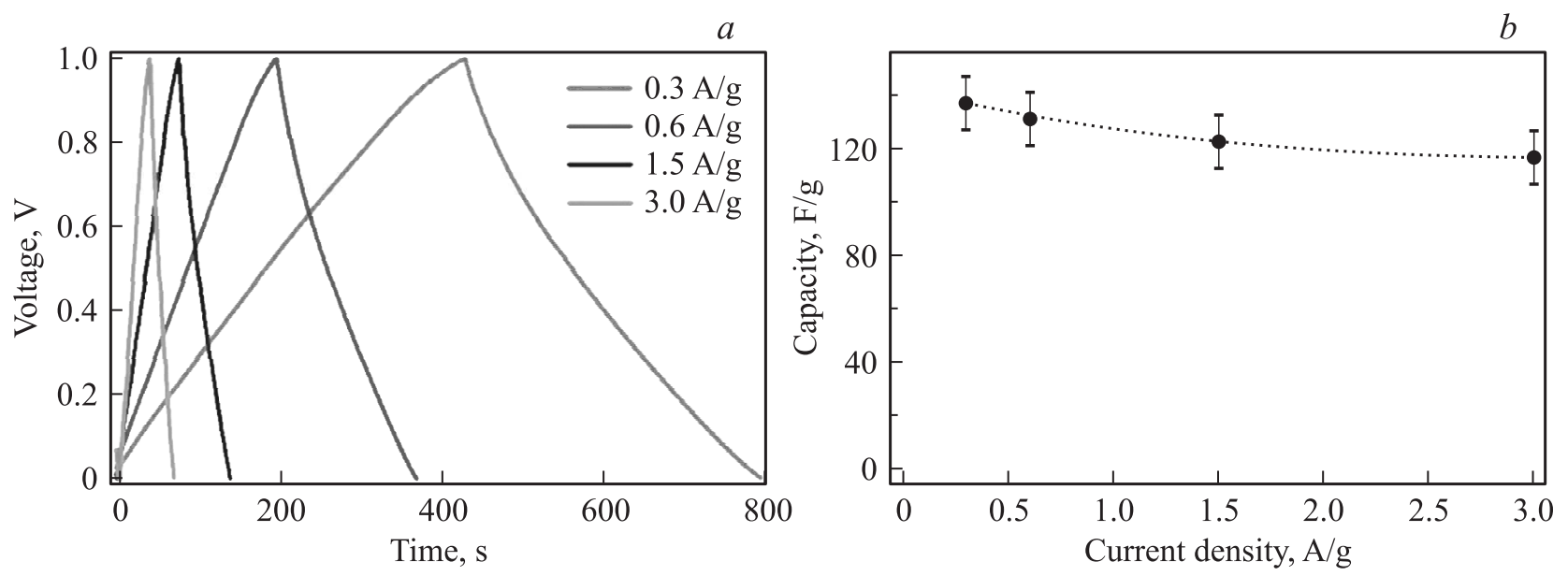

Рис. 6. Гальваностатические кривые заряда/разряда при переменных плотностях тока $300,600 \mathrm{~mA} / \mathrm{g}, 1.5$ и $3 \mathrm{~A} / \mathrm{g}$ (a) и соответствующая им удельная емкость $(b)$. 
Полученные при $600^{\circ} \mathrm{C}$ углеродные нанооболочки были протестированы в качестве электродов для суперконденсатора. Электрохимические измерения показали, что удельная емкость первого цикла составила $130 \mathrm{~F} / \mathrm{g}$, а по истечении 800 циклов деградация составила 23\% от первоначальной.

\section{Список литературы}

[1] H. Marsh, E.A. Heintz, F. Rodriguez-Reinoso. Introduction to Carbon Technology. Universidad de Alicante. Secretariado de Publications, Alicante. Spain (1997). P. 672.

[2] C.N.R. Rao, B.C. Satishkumar, A. Govindaraj, M. Nath. Chem. Phys. Chem. 2, 78 (2001).

[3] H. Dai. Surf. Sci. 500, 218 (2002).

[4] V.N. Popov. Mater. Sci. Eng. R43, 61 (2004).

[5] B. El Hamaoui, L. Zhi, J. Wu, U. Kolb, K. Mullen. Adv. Mater. 17, 2957 (2005).

[6] A. Vinu, M. Miyahara, T. Mori, K. Ariga. J. Porous Mater. 13, 379 (2006).

[7] M. Hartmann, A. Vinu, G. Chandrasekar. Chem. Mater. 17, 829 (2005).

[8] A. Vinu, C. Streb, V. Murugesan, M. Hartmann. J. Phys. Chem. B 107, 8297 (2003).

[9] W. Wang, D. Yuan. Sci. Rep. 4, 5711 (2014).

[10] J.N. Wang, L. Zhang, J.J. Niu, F. Yu, Z.M. Sheng, Yu.Z. Zhao, H. Chang, C. Pak. Chem. Mater. 19, 453 (2007).

[11] X.X. Wang, Z.H. Tan, M. Zeng, J.N. Wang. Sci. Rep. 4, 4437 (2014).

[12] J.N. Wang, Y.Z. Zhao, J.J. Niu. J. Mater. Chem. 17, 2251 (2007).

[13] S.C. Smith, D.F. Rodrigues. Carbon. 91, 122 (2015).

[14] P. Simon, Y. Gogotsi. Nature Mater. 7, 845 (2008).

[15] L.G.H. Staaf, P. Lundgren, P. Enoksson. Nano Energy 9, 128 (2014).

[16] K. Xie, X. Qin, X. Wang, Y. Wang, H. Tao, Q. Wu, L. Yang, Z. Hu. Adv. Mater. 24, 347 (2012).

[17] G. Li, L. Xu, Q. Hao, M. Wang, Y. Qian. RSC Advances. 2, 284 (2012).

[18] J.R. Miller, R.A. Outlaw, B.C. Holloway. Science 329, 1637 (2010).

[19] Y. Ma, Z. Hu, K. Huo, Y. Li, Y. Hu, Y. Liu, J. Hu, Yi Chen. Carbon. 43, 1667 (2005).

[20] G. Radhakrishnan, P.M. Adams, L.S. Bernstein. Thin Solid Films 515, 1142 (2006).

[21] T. Azami, D. Kasuya, T. Yoshitake, Y. Kubo, M. Yudasaka, T. Ichihashi, S. Iijima. Carbon 45, 1364 (2007).

[22] A.V. Sosunov, L.V. Spivak. Phys. Solid State 58, 1371 (2016).

[23] B. Xu, D. Zheng, M. Jia, H. Liu, G. Cao, N. Qiao, Y. Wei, Y. Yang. Mater. Lett. 143, 159 (2015).

[24] Z. Li, M. Jaroniec, P. Papakonstantinou, J.M. Tobin, U. Vohrer, S. Kumar, G. Attard, J.D. Holmes. Chem. Mater. 19, 3349 (2007).

[25] B. Xu, J. Guo, X. Wang, X. Liu, H. Ichinose. Carbon 44, 2631 (2006).

[26] G. Li, H. Yu, L. Xu, Q. Ma, C. Chen, Q. Hao, Y. Qiana. Nanoscale 3, 3251 (2011).

[27] S.J. Teng, J.N. Wang, X.X. Wang. J. Mater. Chem. 21, 5443 (2011).

[28] A.H. Lu, W.C. Li, E.L. Salabas, B. Spliethoff, F. Schuth. Chem. Mater. 18, 2086 (2006).
[29] M. Zheng, Y. Liu, S. Zhao, W. He, Y. Xiao, D. Yuan. Inorg. Chem. 49, 8674 (2010).

[30] J.I. Sohn, Y.-Su Kim, C. Nam, B.K. Cho, T.Y. Seong, S. Lee. Appl. Phys. Lett. 87, 123115 (2005).

[31] R. Zhao, T. Afaneh, R. Dharmasena, J. Jasinski, G. Sumanasekera, V. Henner. Phys. B 490, 21 (2016).

[32] R. Zhao, R. Jayasingha, A. Sherehiy, R. Dharmasena, M. Akhtar, J.B. Jasinski, S.-Y. Wu, V. Henner, G.U. Sumanasekera. J. Phys. Chem. 119, 20150 (2015).

[33] A.C. Ferrari. Solid State Commun. 143, 47 (2007).

[34] M.S. Dresselhaus. Annu. Rev. Condens. Matter Phys. 1, 89 (2010).

[35] S. Reich, C. Thomsen. Phil. Trans. R. Soc. Lond. A 362, 2271 (2004).

[36] M.A. Pimenta. Phys. Chem. Chem. Phys. 9, 1276 (2007).

[37] R. Podila. ACS Nano 6, 5784 (2012). 